\title{
A DESCRIPTION OF TWO APPROACHES TO INSTRUCTION IN A SURVEY COURSE IN ART HISTORY
}

\section{Mercedes Thompson}

This study developed from an interest in the possibilities of applying Feldman's ideas in his two books (Becoming Human Through Art: Aesthetic Experience in the School and Varieties of Visual Expressions: Art as Image and Idea) to the introductory survey course in art history at North Carolina Central University, which used Janson's A Basic History of Art as a text. Through cooperation of the art history instructor, it became possible to modify the course midway in the academic term and to introduce Feldman's ideas. This cooperation enabled the investigator to accomplish three things: to confer with the instructor about the existing course; to share modestly in the planning of the "Feldman" phase; and to act as a participant observer in the class meetings. The problem for the study then became one of description. Four main questions were established: (1) What were the major administrative and "structural aspects" of the course?; (2) Who were the students and what was their "readiness" for a college course in art history?; (3) What was the nature of the course as "planned instruction" before and after the course was modified to include the Feldman type art criticism?; (4) What was the course as a "learning experience" for the students?

\section{Procedure}

I wanted to use Sevigny's approach "triangulated Inquiry" and "Participant Observation," as a resource. Sevigny's (1977) study, titled "Triangulated Inquiry: An Alternative Methodology for Study of Classroom Life," focused on what he referred to as "the interacting multiplicity of variables," of a single social classroom unit. Participant observation in this investigator's study represented two of four stances employed by Sevigny: "the participant-as-observer," and the participant as "complete observer." The first question concerning administrative and structural factors was approached through researching the University's facilities (bulletins and computer files), by holding conferences with key persons (the academic administrators, instructor, and Director of Research and Development), and by holding one academic semester of trial research followed by one semester of actual research, in order to collect various data needed under the following five categories in the description of the students' readiness to study art history at entry: demographic (birth-place, grade schools attended, ethnicity, religious preference, etc.); academic and scholastic aptitude (SAT scores and High School Rank); experience with art before entering the University (grade schools, high schools, and other institutes of higher learning ); knowledge and attitude about art (the Eisner Art Inventories); and ability to understand and talk about art objects, before and after the course was modified (the investigator-built essay test). These data were collected and synthesized using charts and written descriptive groupings for analyses. The second question that of describing the students, was more complex. The admissions data, secured, charted, and analyzed into groupings, were classified by rank with references to students' "readiness" at entry. McFee's perception-delineation theory provided the construct for characterizing each student with reference 
to four categories: "Most Ready" - high academic - greater preparation; "Ready" - high academic - lesser preparation; "Moderately Ready" - low academic - greater preparation; and "Least Ready" - low academic - lower preparation; and for understanding responses and reactions regarding the course before and after it was modified. Then, using a simple random process, four of the thirty-four students in the actual study were selected as subjects and four as alternates. Two of the subjects were Art Education majors, one was majoring in Accounting, and the other in Criminal Justice. One alternate was majoring in Art Education, one in Visual Communications (an area in the Visual Art Program at the University), one in Accounting, and one in Business Administration. Eisner's Art Information and Art Attitude Inventories were used to assess the class membership's understanding and attitude about the field of art when they entered the course. An investigator-built essay test was used to assess the subjects' understanding, responses, and reactions toward art criticism. Descriptive statistical techniques were employed to organize, analyze, and chart the data secured from Eisner's "art inventories," i.e.:

frequency distributions, grouping of data, frequency polygons, comparisons of differences between means, and correlations by the Pearson Whole Method and by direction of increase and decrease in mean scores by grade level. The essay test, administered the first time at the beginning of the academic term, was scored by four judges based on Tuckman's use of definitions by Bloom et al's four steps in a thinking process, i.e.: application, analysis, synthesis, and evaluation. These scores were averaged and expressed as percentages for analyzing the similarities and differences in the subjects' perceptions and reactions regarding art criticism. The multiple collection of data from all categories was summarized in profile form for analyses. Protocols were also included from both Eisner's inventories and the investigator-built test to support other data. The third question, the description of the course as planned instruction was based upon the collection of data secured from conferences with the instructor and the chairperson of the Department of Art with reference to administrative facts, goals, objectives, content, and teaching methodology. Both cognitive and affective understandings, and competence for whatever purposes were represented. Bloom et al's $(1956,1964)$ taxonomies were used as models for classifying learning. Detmer's (1980) and Feldman's $(1967,1970)$ studies were used as models for identifying course content. Anecdotal notes, tape recordings, checklists (systematic encoding), worksheets, and participant observation were used in securing these data, which were defined, grouped, and charted for analyses in understanding how closely the subjects' perceptions and reactions agreed with the investigator's with reference to the various aspects of the two approaches to instruction in the course. The fourth question regarding the description of the course as experienced by students was based upon the collection of information about the students when they entered the course and their personal "testimonies" pertaining to how they perceived and felt about the four "aspects" of the course before and after it was modified. A special session, held during a free period after class, enabled the investigator to focus directly on the subjects and their alternates. Participant observation; exam scores and sample items; a questionnaire administered at the end of the academic term and again in retrospect one academic term after the course ended; interviews with the instructor and the students; spontaneous conversations; and the scores from a second administration of the investigator-built essay test provided the information needed in interpreting the similarities and differences in the subject's perceptions and feelings regarding the various aspects 
of the two approaches to instruction in the course, and established a procedure for checking the continuity between the various perceptions and reactions. Flander's model of classroom interaction provided the four dimensions needed in narrowing the factors that were observed and provided a standard for interpreting what was observed. Tuckman's standards for criterion-referenced tests and the University grading system provided the guidelines for interpreting exam scores. McFee's theoretical model pertaining to "readiness" provided the categories throughout the study for interpreting all of the factors pertaining to the students' readiness to respond to the course requirements: classroom atmosphere, visual media, information handling, and feedback. Renick's writings on "Art Criticism" were used as instructions on how to criticize works of art. Tape recordings, anecdotal records, and systematic encodings were used to collect the various emic data. A t test was used to analyze the scores from the first administration of the questionnaire. Chi square was used to interpret the second set of scores from the questionnaire. Charts, protocols, and profiles were used in charting and organizing the data for analyses.

\section{Summary of Findings and Implications}

Very briefly, the overall findings revealed the following information: First, the course is a "selective survey of major works of art as illustrations of the influence of environment, social and religious organizations, and historic events," and was limited exclusively to "a study of Western civilizations" before it was modified midway in the academic term with Feldman's art criticism component and his contextual ideas about teaching art history. It is one of six that can be identified as having General Education Program status. It is taught each semester, due to the great demand from the students. Second, the students - from across the disciplines - differed with reference to demographic status, scholastic aptitude, academic ability, prior knowledge and attitudes about the field of art and art criticism, and previous formal instruction and experience in art. Thus, their readiness to study college art history can be characterized as varied in degree and type. Each of the students in the class membership fell in one of the four categories indicated earlier: "Most Ready," "Ready," "Moderately Ready," and "Least Ready." When compared with a norm - Elliot Eisner's 1966 study of college groups - the North Carolina Central group responded less well by grade level on the Art Information Inventory, which measured low level cognitive abilities, than did Eisner's group, but responded more positively than did Eisner's group on the Art Attitude component. The Eisner college group's socioeconomic status was higher than the North Carolina Central group's. Third, it was disclosed that both the "conventional" and the "modified" approaches to the course included historical, philosophical, structural, and critical content, although the goals (purposes), objectives, content, and teaching methodology are explicitly and implicitly different. The "conventional" approach was more limited in scope and breadth than the "modified" Feldman type approach. The "modified" approach included instructions, systematically emphasized, in how to study and criticize works of art - something the conventional approach did not do.

Fourth, when taught as an entity in itself or as a combined effort, the course provided some interesting positive success and the students were well aware of the differences in the four structural aspects of the two approaches to instruction in the course. Although all of the subjects stated that they enjoyed the experience in the course regardless of the approach employed, the two art 
majors believed that the history and the art criticism components should be combined throughout a survey course. One of the non-art majors believed that the idea should be left strictly to the instructor who indeed, to a great extent, is held accountable for the students' success or failure in the course. The other non-art majors believed that the two components should be combined only if the students taking the course have developed competence in handling the visual elements and principles in art. The alternates agreed with the art majors - that the two components should be combined so that students can better understand the works of art. All but one of the students seemed to perceive the course as a means to an end and for some distant purpose, not as an immediate aesthetic experience to be enjoyed for itself reminiscent of Dewey's ideas about "experience." The instructor persisted that the two components should remain separate, since the purposes of the two are different.

\section{REFERENCES}

Bloom, Benjamin S., Englehart, Max D., Furst, Edward J., Walker, H., and Krathwohl, David R. Taxnonomy of Educational Objectives: The Classification of Educational Goals, Handbook I: Cognitive Domain. New York: Longman, 1956.

Bulletin of North Carolina Central University: Durham, North Carolina. Raleigh: Contemporary Lithographics, Inc., 1980.

Detmers, William R. A Conceptual Model for Curriculum Planning and Evaluation in the Visual Arts. Studies in Art Education, 1980 21, 58-59.

Eisner, Elliot W. The Development of Information and Attitude Toward Art at the Secondary and College Level. Studies in Art Education. 1966 8, 45-51.

Feldman, Edmund B. Becoming Human Through Art: Aesthetic Experiences in the School. Englewood Cliffs: Prentice Hall Inc., 1970.

- Varieties of Visual Experience: Art as Image and Idea. Englewood Cliffs: Prentice-Hall, Inc., 1967.

Flanders, Ned A. Analyzing Teaching Behavior. Reading: Addison-Wesley Publishing Company, 1970.

Janson, H. W. And Samuel Cauman. A Basic History of Art. Englewood Cliffs: Prentice-Hall Inc., 1971.

McFee, June King. Preparation for Art. Belmont: Wadsworth Publishing Company, Inc., 1961.

Renick, Patricia. Art Criticism. Writings for Classroom Use. University of Cincinnati, Cincinnati: Ohio, 1971.

Sevigny, Maurice J. Triangulated Inquiry: An Alternative Methodology for the Study of Classroom Life. Review of Research in Art Education, 19788.

Tuckman, Bruce W. Measuring Educational Outcomes: Fundamentals of Testing. New York: Harcourt Brace Jovanovich, Inc., 1975. 